\title{
Grundfagligt Speciale: An advanced laboratory-research course for nonphysicists taught by physicists
}

Gordon, R A; Lebech, Jens; Mygind, Jesper; Pedersen, Niels Falsig; Lynggaard-Jensen, Anders; Petersen, H. G.

Published in:

American Journal of Physics

Link to article, DOI:

$10.1119 / 1.11693$

Publication date:

1979

Document Version

Publisher's PDF, also known as Version of record

Link back to DTU Orbit

Citation (APA):

Gordon, R. A., Lebech, J., Mygind, J., Pedersen, N. F., Lynggaard-Jensen, A., \& Petersen, H. G. (1979).

Grundfagligt Speciale: An advanced laboratory-research course for nonphysicists taught by physicists. American Journal of Physics, 47(1), 52-55. https://doi.org/10.1119/1.11693

\section{General rights}

Copyright and moral rights for the publications made accessible in the public portal are retained by the authors and/or other copyright owners and it is a condition of accessing publications that users recognise and abide by the legal requirements associated with these rights.

- Users may download and print one copy of any publication from the public portal for the purpose of private study or research.

- You may not further distribute the material or use it for any profit-making activity or commercial gain

- You may freely distribute the URL identifying the publication in the public portal 


\title{
Grundfagligt speciale: An advanced laboratory-research course for nonphysicists taught by physicists
}

\author{
R. A. Gordon, J. Lebech, J. Mygind, and N. F. Pedersen \\ Physics Laboratory I, The Technical University of Denmark, DK-2800 Lyngby, Denmark
}

\author{
A. Lynggaard-Jensen and H. G. Petersen \\ Ostenfeld Kollegiet, The Technical University of Denmark, DK-2800 Lyngby, Denmark \\ (Received 4 October 1977; accepted 29 March 1978)
}

\begin{abstract}
The pedagogical and research advantages of an advanced laboratory-research course for nonphysicists taught by physicists are discussed. The practical considerations which determine the structure and content of such a course are emphasized with particular attention given to those features which would be most helpful to others contemplating a similar course. A successful example of such a course developed by the authors is discussed in detail.
\end{abstract}

\section{INTRODUCTION}

Physics lecture courses for nonphysics students from a large number of other disciplines such as geology, biology, medicine, etc., have been discussed in detail in the literature. ${ }^{1-4}$ Such lecture courses have been very well received and have clearly shown that the subject matter of physics can be profitably presented in a more general context than that normally found in conventional physics courses. In spite of this success, there has been very little work describing physics laboratory courses for nonphysics students in which a presentation of the experimental side of physics in a more general context has been similarly emphasized. In particular, there have been no published accounts of a laboratory course of this type at the applied research-oriented level where the advantages of such a presentation to the nonphysics student would be most obvious and direct. ${ }^{5}$ It is the purpose of this article to describe an interdisciplinary laboratory course of this type (Grundfagligt Speciale) ${ }^{6}$ in which the emphasis is placed on the application of the experimental methodology of physics to problems of potential research interest to the nonphysicist. Special attention is given to those practical considerations which determine the structure and content of such a course with particular emphassis on the unique pedagogical and research possibilities which can be conveniently realized. A number of other features likely to be useful to those contemplating a similar course, or interdisciplinary courses in general, are also treated in detail.

\section{STRUCTURE OF THE COURSE}

The structure of the course was strongly influenced by the fact that most of the experimental methods of physics likely to be of potential research interest to the nonphysicist tend to be instrumentally more difficult, requiring both a longer learning time and a thorough familiarity with the basic concepts of physics on the part of the nonphysics student. This is by no means a disadvantage, however, since the more sophisticated experimental methods frequently offer the most promising interdisciplinary research possibilities and can, in fact, be readily assimilated by a group of two or three students concentrating on a single experimental technique for an entire semester. In practice, different groups of students could concentrate either on dif- ferent experimental techniques or on one of several different projects based on the same experimental technique. In order to more fully master a given experimental technique, it is desirable that the nonphysics students have a previous educational background corresponding to that obtained, for example, by competent senior or first-year graduate students at most American universities including both a thorough familiarity with basic physics as well as a mature appreciation of the research possibilities within their own nonphysics discipline. The latter requirement is, of course, essential in a course such as Grundfagligt Speciale where the students are intentionally encouraged to select experiments and interpret measurements relevant to their own field. One natural consequence of a laboratory course for nonphysics students at this level is that it provides a wellmotivated opportunity for the mature nonphysics student to develop an active practical experimental familiarity with physics before being totally absorbed in nonphysics course work. The plan of the course was, in fact, developed with precisely this feature in mind as can be seen in Fig. 1 where the overall linear progression of the course from an initial learning period to a detailed concentration on a single research-oriented application is clearly shown. More specifically, the object of the initial training period was to familiarize the students with the operation and potential applications of a given experimental technique in sufficient detail that they could carry out standard measurements on their own and at the same time acquire an active practical awareness of which modifications of the experimental technique could be made for specific applications.

It is worthwhile pointing out that the course plan shown in Fig. 1 is essentially the Keller ${ }^{7}$ PSI self-paced system of instruction adapted to an advanced laboratory-research course. One difference, however, is the fact that the selfpacing feature, whereby the students must demonstrate mastery of a given part of the course before proceeding to the next, enters in a completely natural way as a consequence of the linear-progression structure necessary to teach a single experimental technique. Another important difference is that there is a good deal of overlap between the various course units shown in Fig. 1. In spite of the fact that such an overlapping structure has not, to our knowledge, been incorporated in a PSI course before, it is probably essential in a laboratory-research course such as Grundfagligt Speciale where the learning process necessarily 


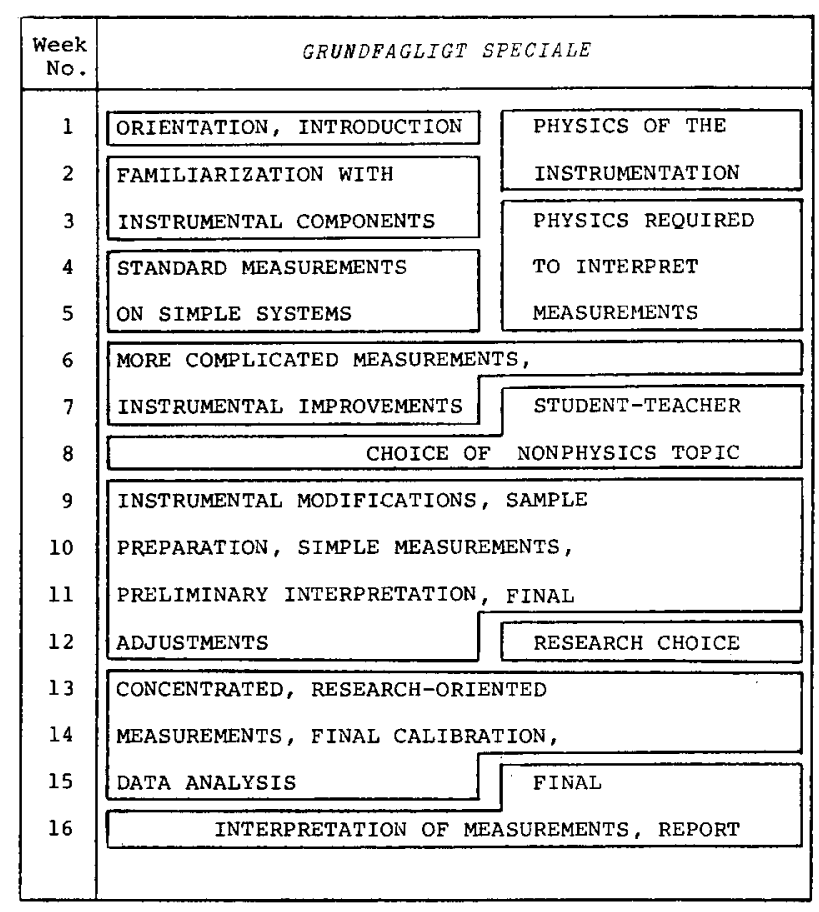

Fig. I. Schematic diagram depicting the overlapping Keller PSI instructional form of the one-semester interdisciplinary Grundfagligt Speciale course described in the text. This figure shows the distribution of the student's time in the $12 \mathrm{~h} /$ week during which they carried out experimental work (the left side of Fig. 1) or participated in informal lecture-discussion periods with the physicist teachers (the right side of Fig. 1). The students were also expected to devote a lesser amount of time to reading and laboratory preparation on their own.

requires a large amount of coupling between qualitatively different parts of the course.

In practice, the course plan described here entails a good deal of direct personalized instruction on the part of the physics teachers. In addition, both the students and the teachers involved will probably find it necessary to devote a good deal of original thought and reading time to potential applications of the experimental technique if the joint student-teacher choice of the final research topic is to be mutually satisfactory. Although such multiple instructional functions could be satisfied by a single physics faculty member, it may be more effective in practice to request a number of other physics (and nonphysics) faculty members to assume the instructional burden of those portions of the course which lie within their respective specializations. A broader faculty representation will also be necessary if the nonphysics portion of the course is to receive a sound critical evaluation. This has an additional practical advantage in making it easier to obtain some of the specialized nonphysics instrumentation necessary to carry out research-level measurements. It might also be pointed out that such a collaboration with other nonphysics faculty members could be used by an enterprising physics department as a simple means of exploring different interdisciplinary-research possibilities without the necessity of costly long-term commitments in faculty time and department apparatus. We now describe how the various features of course structure described above will play a strong role in determining the content of the course by considering a successful example of Grundfagligt Speciale developed by the authors.

\section{CONTENT OF THE COURSE}

The relative novelty of the course made it reasonable to begin with a single experimental technique of known utility to the nonphysics discipline in question and which was familiar to several different physics faculty members. In our case, ESR was a natural first choice reflecting both the chemistry background of the expected students as well as the extensive practical experience of the physics faculty with various techniques of $\mathrm{rf}$ spectroscopy. ${ }^{8}$ Equally advantageous was the fact that ESR was not presented experimentally in the students previous chemistry courses and could be taught using instrumentation which was already available at Physics Laboratory I. Since the pedagogical aspects of teaching ESR have been treated in the literature, ${ }^{9}$ we will consider only those features of the technique which are relevant to an experimental presentation of ESR in an interdisciplinary laboratory-research course.

The initial half of the course (see Fig. 1) was devoted to a thorough instruction in the operation of a standard $X$ band ESR spectrometer. This was accomplished by guiding the student through different measurements of the microwave circuit properties of the various components of ESR spectrometers. This was followed by the construction of ESR spectrometers of increasing sensitivity and complexity, employing phase-sensitive detection, magnetic field modulation, microwave bridges, superheterodyne receivers, etc. All of these spectrometers could be conveniently assembled on a single table top as shown in Fig. 2. The various spectrometers constructed were used to measure a series of successively weaker signals intentionally chosen both to motivate the instrumental improvements as well as to demonstrate a number of important ESR phenomena. Thus, for example, such ESR phenomena as contact- and dipole-hyperfine interactions, quadrupole and exchange splitting, saturation effects, itinerant unpaired electrons, etc., were illustrated using readily prepared samples, e.g., diphenylpicrylhydrazyl in benzene, $\mathrm{CuSO}_{4}$, paper ash, transition-metal aqueous solutions, semiquinones, etc. The interpretation of the ESR spectra was facilitated by informal student-teacher lecture sessions which overlapped the relevant measurements in time (cf., Fig. 1) and which lead to an active familiarity of the students with the standard ESR textbooks of Poole, ${ }^{10}$ and Alger, ${ }^{11}$ and Wertz and Bolton. ${ }^{12}$ The amount of theoretical and experimental subject matter which the students can assimilate is, of course, dependent on the time which they have available but we have found that the program described above is entirely feasible in the first half of a one-semester elective course corresponding to $12 \mathrm{~h} /$ week of laboratory work and a

Fig. 2. Table-top $X$-band superheterodyne ESR spectrometer built by the students showing the Gunn diode rf source and the pump used to regulate the flow of hydroquinone (a) and alkaline (b) solutions into the mixing cell.

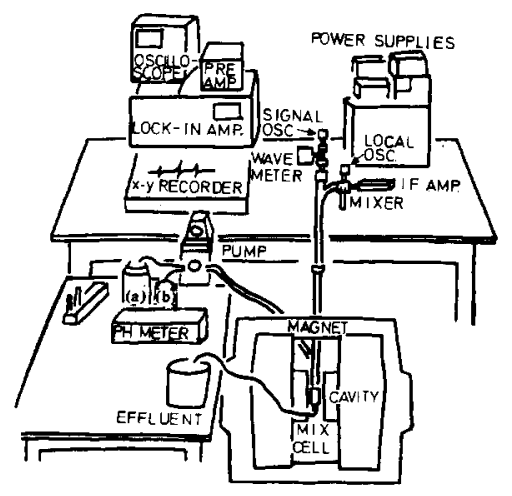



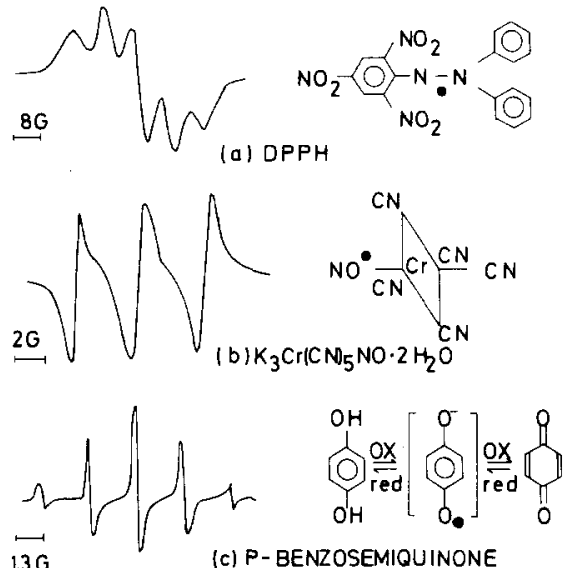

1.36

(c) P-BENZOSEMIQUINONE
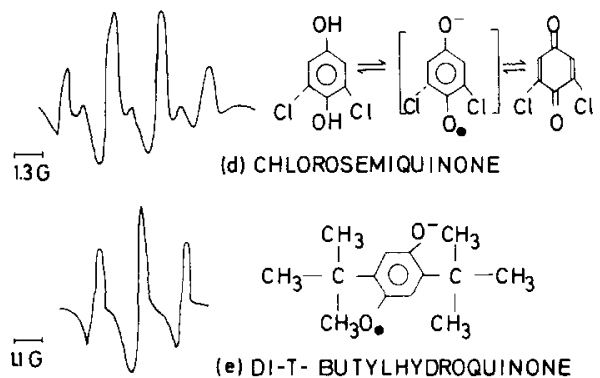

Fig. 3. Simple ESR spectra from unpaired electron spins in several different liquid solutions recorded using the spectrometer shown in Fig. 2. The ESR spectra in Figs. 3(a) and 3(b) were recorded without the flow system and show the contact hyperfine interaction of an electron spin located between the $\mathrm{N}$-atoms [in Fig. 3(a) for a benzene solution] and at the site of the $N O$-radical [in Fig. 3(b) for an aqueous solution]. Figures $3(\mathrm{c})-3(\mathrm{e})$ were recorded using the flow system to study intermediate reaction products of several different hydroquinone and alkaline solutions. These last three spectra represent the contact hyperfine interaction of an unpaired electron spin with four [Fig. 3(c)], three [Fig. 3(d)], and two [Fig. $3(\mathrm{c})$ ] equivalent hydrogen atoms on the central benzene rings. The additional subsidiary resonances in Fig. 3(d) are due to trace impurities of dichlorosemiquinone whose presence was also confirmed by thin-layer chromatography.

somewhat lesser amount of time spent in reading and laboratory preparation. Although a course load of this size is probably larger than that normally allocated to laboratory courses at many American universities, for example, it could be formally distributed over a two-semester course or reduced somewhat in its depth of detail without defeating the primary purpose of the course.

Near the end of the first half semester, a number of contacts and visits with chemical laboratories using ESR were arranged which helped to provide a more definite impression of the chemical possibilities inherent in ESR. Based on these contacts as well as on their own'study of the research literature, the students were able to make a number of concrete proposals regarding those chemical applications of ESR in which they were most interested. Both the instrumental requirements of the various proposals and the advanced instrumental and technical support which the physicist teachers could offer were used as criteria in selecting a single application to be studied in the last half semester of the course. In our case, the students decided to study transient chemical reactions in the liquid phase which required an efficient flow system and an optimized superheterodyne receiver. The flow system was used to measure free electron ESR signals of various intermediate re- action products formed during the chemical reaction process. This enabled the students to study a number of short-lived chemical reactions which were otherwise too rapid to be observed by normal chemical methods. Some of the simpler components could be built in the department workshop but the more specialized, expensive components of the flow system such as the pump and the chemical mixing cell were borrowed from other nonphysics departments. A number of different standard chemical reactions involving short-lived radicals (see Fig. 3) were investigated using ESR. This provided a check of spectrometer capabilities and practical information regarding those chemical systems which would be most feasible for a concentrated flow-system study in a research context. The final exclusively research-oriented phase of the course dealt with a quantitative experimental reexamination of previous measurements of intermediate-reaction products in hydroquinone solutions. ${ }^{13}$ This particular choice also made it possible to use the earlier published results as a means of checking the validity of the measurements obtained. More research-oriented measurements could, of course, be carried out depending on the particular educational background of the individual groups and the nature of the measurements themselves. The course itself was concluded by the writing of a report by the students in sufficient detail that other students and teachers would be able to repeat the work carried out without difficulty. The more specialized chemistry portions of the report were checked by an external chemistry faculty member and the final grade evaluation given in a "pass-fail" grading system.

\section{DISCUSSION}

The laboratory-research course described here has been well received by both the students and the faculty members involved. This fact, in addition to the large number of favorable comments from all those less directly involved is, we feel, a clear indication that a course of this type satisfies a real need in providing both the students and the teachers with a unique form of interdisciplinary collaboration of long-term benefit to both. More important, perhaps, is that these advantages can be readily obtained within an extremely flexible course structure easily adapted to fit the special requirements of individual institutions.

\section{ACKNOWLEDGMENTS}

Two of the authors (A.L.-J. and H.G.P.) would like to thank Professor J. A. Pederson at Aarhus University for a number of helpful discussions and the loan of the mixing cell. The departments of Organic Chemistry, Chemistry Laboratory A, and Biochemical Engineering at the Technical University of Denmark are also gratefully acknowledged for providing us with a number of research facilities.

${ }^{1}$ G. M. Julian and A. M. Stueber, Am. J. Phys. 42, 556 (1974); B. S. Henderson and M. A. Henderson, ibid. 44, 519 (1976).

${ }^{2}$ E. L. Chaney, W. R. Hendess, G. S. Ibbott, and M. N. Frank, Am. J. Phys. 42, 465 (1974); M. G. Hare, ibid. 41, 956 (1973).

${ }^{3}$ R. A. Leacock and H. I. Sharlin, Am. J. Phys. 45, 146 (1977); A. P. French and E. L. Jossen, ibid. 44, 1449 (1976).

${ }_{4}^{4}$ M. K. Garrity, Am. J. Phys. 45, 1206 (1977); R. S. Newrock, ibid. 46, 32 (1978). 
${ }^{5}$ More precisely, there have been no laboratory courses in which nonphysics students both learn and apply a specific experimental method of physics to problems of interest to their own nonphysics discipline in a one-semester course. As discussed in the text, a course of this type has a number of interdisciplinary advantages not to be found in courses employing a conventional course structure in which, for example, a large number of different experimental techniques are presented in one semester or in which a single experimental technique is chosen to be the subject of a master's degree program: A. H. Clark, Am. J. Phys. 44, 696 (1976); V. Elings and D. Phillips, ibid. 41, 570 (1973).

${ }^{\natural} \mathrm{A}$ Grundfagligt Speciale (Basic Special) program in which students at the advanced undergraduate level are required to take a half-time semester laboratory course either in their own or in a different discipline has been in operation for several years at the Technical University of Denmark. This is the first time, however, that a course specifically emphasizing physics laboratory techniques has been adapted to such a program.

${ }^{7}$ T. C. Taveggia, Am. J. Phys. 44, 1028 (1976); G. D. Putt, ibid. 45, 472 (1973).
${ }^{8}$ The purpose of the description of ESR presented in the text is to give an illustration of some of the practical details likely to be found in the development of research laboratory courses in general. A particular application of a physics laboratory technique will, of course, involve a number of details specific to the application itself and, in the case of applications to more distantly related fields, e.g., medicine, may require a greater initial effort on the part of the physics faculty in helping to choose a research topic.

${ }^{9}$ L. A. Collins, M. A. Morrison, and P. L. Donoho, Am. J. Phys. 42, 560 (1974); R. E. Norberg, ibid. 33, 71 (1965).

${ }^{10} \mathrm{C}$. C. Poole, Jr., Electron Spin Resonance: A Comprehensive Treatise on Experimental Techniques (Interscience, London, 1967).

"R. S. Alger, Electron Paramagnetic Resonance: Techniques and Applications (Interscience, London, 1967).

12J. E. Wertz and J. R. Bolton, Electron Spin Resonances: Elementary Theory and Practical Applications (McGraw-Hill, Düsseldorf, 1972).

${ }^{13}$ B. G. Segal, M. Kaplan, and G. K. Fraenkel, J. Chem. Phys. 43, 4191 (1965). 